\title{
QUALIDADE FISIOLÓGICA DE SEMENTES DE FEIJÃO CRIOULO PROVENIENTE DE DIFERENTES LOCALIDADES
}

\author{
Thaise dos Santos Berto ${ }^{1}$, Natalia Marinho Silva Crisostomo ${ }^{1}$, Marcus Gabriel de Carvalho Ramos ${ }^{1}$, Carlos \\ Luiz da Silva', Emanuelle Almeida da Costa', João Luciano de Andrade Melo Junior ${ }^{2}$, Luan Danilo Ferreira \\ de Andrade $\mathrm{Melo}^{3}$, João Correia de Araújo $\mathrm{Neto}^{3}$
}

\author{
${ }^{1}$ Alunos do Curso de Agroecologia do Centro de Ciências Agrárias (CECA), Universidade Federal de Alagoas (UFAL). E-mail: \\ thaiseberto7@gmail.com \\ ${ }^{2}$ Doutorando do Programa de Pós-graduação em Produção Vegetal do Centro de Ciências Agrárias (CECA) e Professor voluntário do \\ Curso de Agroecologia, Universidade Federal de Alagoas (UFAL). E-mail: luciiano.andrade@yahoo.com.br \\ ${ }^{3}$ Professores do Centro de Ciências Agrárias (CECA), Universidade Federal de Alagoas (UFAL). E-mail: Iuan.danilo@yahoo.com.br
}

RESUMO: O trabalho foi desenvolvido com o objetivo de caracterizar a qualidade fisiológica de sementes crioulas de feijão comum cultivadas nos municípios de São João-PE, Lajedo-PE, Caetés-PE e União dos PalmaresAL. As sementes foram doadas por agricultores familiares das respectivas cidades. $O$ trabalho foi conduzido no Laboratório de Propagação de Plantas pertencente ao Centro de Ciências Agrárias (CECA), Campus Delza Gitaí, da Universidade Federal de Alagoas (UFAL). Os parâmetros avaliados foram: teor de água (TA), peso de mil sementes (PMS), primeira contagem de emergência (PCE), emergência (EMER) de plântulas, índice de velocidade de emergência (IVE), comprimento da parte aérea (PA) e raiz e massa seca de plântulas. 0 delineamento experimental utilizado foi em blocos casualizados, com quatro repetições de 50 sementes por tratamento. As variedades crioulas de feijão comum apresentam percentual de emergência acima dos padrões mínimos exigidos para comercialização. O lote de sementes proveniente de São João-PE apresentou qualidade fisiológica superior em relação aos demais municípios.

Palavras-chave: Agricultura familiar, Phaseolus vulgaris L., produção, germinação, vigor

\section{Physiological quality of beans seed crioulo from different locations}

ABSTRACT: The objective of this work was to characterize the physiological quality of seeds of crioulo bean cultivars grown in the municipalities of São João-PE, Lajedo-PE, Caetés-PE and União dos Palmares-AL. Creole seeds were donated by family farmers in their respective states. The work was carried out in the Laboratory of Plant Propagation belonging to the Center of Agricultural Sciences (CECA), Delza Gitaí Campus, Federal University of Alagoas (UFAL). The parameters evaluated were: water content, thousand seed weight, first emergency count (PCE), seedling emergence (EMER), emergence velocity index (IVE), shoot length and root and dry mass of seedlings. The experimental design was in randomized blocks, with four replicates of 50 seeds per treatment. The common bean creole varieties present germination percentage above the minimum standards required for commercialization. The seed lot from São João presented superior physiological quality in relation to the other municipalities.

Keywords: Family agriculture, Phaseolus vulgaris L., production, germination, vigor

\section{INTRODUÇÃO}

A produção de feijão comum é realizada por vários tipos de produtores, em muitas regiões do país, utilizando diferentes níveis tecnológicos. Dentre estes produtores, a agricultura familiar é marcada como a grande responsável pela produção de feijão (SILVA; WANDER, 2013). Segundo França et al. (2009), a agricultura familiar seria responsável por $70 \%$ da produção de feijão.

Vários tipos de feijão comum são cultivados no Brasil, dentre eles o carioca, o preto e os especiais, 
em três safras no ano. Esse cenário demonstra a relevância socioeconômica desta cultura para o Brasil, cultivado por pequenos e grandes produtores (AVACI et al., 2010).

A qualidade da semente é expressa pela interação de quatro componentes: genético, físico, fisiológico e sanitário. Sementes crioulas se armazenadas de forma correta e tomando os cuidados durante a produção e colheita o uso dessas sementes surge como uma alternativa para agricultura familiar visando preservar também o banco de germoplasma de uma determinada região (SILVA et al., 2012).

Dentre as variedades crioulas de feijões há grande variação de cores, morfologia e usos. A preferência da utilização de sementes crioulas é atribuída principalmente a características como adaptabilidade, valorização dos costumes, sabor e qualidade das variedades tradicionais, além do baixo custo de produção (PELWING et al., 2008).

As estratégias de conservação, uso, multiplicação e comercialização das sementes crioulas se traduzem em ações, como valorização dos bancos de sementes comunitários e testes para o controle de qualidade das sementes produzidas em comunidades rurais, de maneira que os produtores tenham mais autonomia (CATÃO et al., 2010). Devido à escassez de informações sobre a qualidade fisiológica e física de sementes crioulas de feijão nos estados de Pernambuco e Alagoas, faz-se necessário o desenvolvimento da presente pesquisa.

Com base nisso, o objetivo do trabalho foi caracterizar o potencial fisiológico de sementes crioulas de feijão, cultivadas nos municípios de São João-PE, Lajedo-PE, Caetés-PE e União dos Palmares-AL.

\section{MATERIAL E MÉTODOS}

O trabalho foi conduzido no Laboratório de Propagação de Plantas pertencente ao Centro de Ciências Agrárias (CECA). Foram utilizados sementes de quatro variedades crioulas de feijão, adquiridas em pequenas propriedades rurais (São João-PE, LajedoPE, Caetés-PE e União dos Palmares-AL.) e cedidas pelos produtores, em embalagem de polietileno tereftalato (PET) da safra de 2017/2017.

A avaliação da qualidade fisiológica das sementes foi feita por meio dos seguintes testes e determinações:
a)Teor de água: realizado utilizando quatro subamostras de 50 sementes em latas de alumínio em estufa a $105 \pm 3^{\circ} \mathrm{C}$, por 24 horas e os resultados expressos em porcentagem (BRASIL, 2009).

b)Peso de mil sementes: determinado conforme a fórmula proposta por Brasil (2009), utilizando-se oito repetições de 100 sementes, efetuadas através da pesagem em balança com precisão de 0,001 g.

c)Emergência de plântulas: na avaliação da emergência foram utilizadas 200 sementes, distribuídas em quatro repetições de 50 sementes, semeadas em bandejas $(6,5 \times 19,5 \times 31,0 \mathrm{~cm})$. A porcentagem de emergência foi obtida considerando as plântulas emergidas, aquelas com os folíolos primários expandidos, até a estabilização do teste (9 dias), com os resultados expressos em porcentagem.

d)Primeira contagem de emergência: realizada simultaneamente com o teste de emergência, sendo a porcentagem acumulada de plântulas emersas no quinto dia após a semeadura.

e)Índice de velocidade de emergência (IVE): realizado conjuntamente com o teste de emergência, computando-se as plântulas emersas diariamente até a estabilização da emergência das plântulas, e calculado pela fórmula proposta por Maguire (1962).

f)Comprimento de plântulas: ao final do teste de emergência, dez plântulas normais tomadas ao acaso de cada repetição foram utilizadas para se avaliar o comprimento (da parte aérea e raiz), com auxílio de uma régua graduada em centímetros, sendo os resultados expressos em centímetro por plântula.

h)Massa seca de plântulas: ao final do teste de emergência, as plântulas emersas provenientes de cada tratamento foram colocadas em sacos de papel do tipo kraft e acondicionadas em estufa com circulação de ar forçado, regulada a $65^{\circ} \mathrm{C}$, aonde permaneceram até atingir peso constante. Em seguida, foram pesadas em balança analítica com precisão de $0,0001 \mathrm{~g}$, sendo os resultados expressos em gramas por plântula.

0 delineamento estatístico utilizado foi em bloco casualisado (DBC). Todas as análises estatísticas foram realizadas pelo programa SISVAR, da Universidade Federal de Lavras (FERREIRA, 2011). Os dados obtidos submetidos à análise de variância (ANOVA). Quando houve significância do teste $F$, as médias foram comparadas pelo teste de Tukey a 5\% de probabilidade. 


\section{RESULTADOS E DISCUSSÃO}

Os dados referentes ao teor de água e peso de mil sementes de sementes de feijão crioulo de diferentes localidades estão na Tabela 1. Verifica-se que a variedade de São João-PE apresentou maior peso de mil sementes $(247,2 \mathrm{~g})$, diferindo estatisticamente das demais, enquanto que o menor peso foi observado na variedade de União dos Palmares (221,41 g). Segundo Carvalho e Nakagawa (2012), o peso das sementes fornece informações sobre a sua qualidade e seu estado de maturidade e é diretamente influenciado pela porcentagem de umidade.

Tabela 1. Teor de água (TA) e Peso de mil sementes (PMS) de sementes de feijão crioulas de diferentes localidades.

\begin{tabular}{lll}
\hline Localidade & TA (\%) & PMS (g) \\
\hline São João-PE & $12,50 \mathrm{a}$ & $247,20 \mathrm{a}$ \\
Lajedo-PE & $12,21 \mathrm{~b}$ & $227,50 \mathrm{~b}$ \\
Caetés-PE & $12,38 \mathrm{~b}$ & $228,00 \mathrm{~b}$ \\
União dos Palmares-AL & $11,81 \mathrm{c}$ & $221,41 \mathrm{c}$ \\
CV (\%) & 12,15 & 10,11 \\
\hline
\end{tabular}

Médias não diferem entre si a $5 \%$ de probabilidade pelo teste de Tukey.

$O$ fato dos lotes de sementes serem produzidos de maneiras distintas, dentro das peculiaridades das práticas de cada produtor, possivelmente, pode ter influenciado no seu peso. Segundo Bezerra et al. (2004), em muitas espécies o peso da semente é um indicativo de sua qualidade fisiológica, sendo que em um mesmo lote, sementes leves, normalmente, apresentam menor desempenho do que as pesadas.

Os valores médios de primeira contagem de emergência (PCE), emergência (EMER) e índice de velocidade de emergência (IVE) de plântulas de diferentes variedades de feijão estão apresentados na Tabela 2. O maior percentual de PCE e EMER foi observado nas sementes de São João-PE (25 e 93\%, respectivamente), diferindo das demais localidades. $\mathrm{Na}$ avaliação do IVE, observou-se maior velocidade de emergência nas sementes de São João-PE $(4,27)$, demonstrando maior vigor destas sementes em relação às das demais localidades, indicando que apresentam maior capacidade de originar plântulas mais competitivas nas fases iniciais da cultura. Os menores índices de velocidade foram verificados nas sementes de União dos Palmares-AL, Lajedo e Caetés-PE $(3,15$, 2,94 e 2,89, respectivamente) (Tabela 2).

Tabela 2. Primeira contagem de emergência (PCE), emergência (EMER) e índice de velocidade de emergência (IVE) de plântulas oriundas de sementes de feijão crioulas de diferentes localidades.

\begin{tabular}{llll}
\hline Localidade & PCE (\%) & EMER (\%) & IVE \\
\hline São João-PE & $25 \mathrm{a}$ & $93 \mathrm{a}$ & $4,27 \mathrm{a}$ \\
Lajedo-PE & $5 \mathrm{~b}$ & $70 \mathrm{c}$ & $2,94 \mathrm{~b}$ \\
Caetés-PE & $5 \mathrm{~b}$ & $80 \mathrm{~b}$ & $3,15 \mathrm{~b}$ \\
União dos Palmares-AL & $6 \mathrm{~b}$ & $87 \mathrm{a}$ & $2,89 \mathrm{~b}$ \\
CV $(\%)$ & 10,11 & 14,48 & 15,12 \\
\hline
\end{tabular}

Médias não diferem entre si a $5 \%$ de probabilidade pelo teste de Tukey.

A emergência de plântulas é influenciada pelo vigor das sementes, que é manifestado com mais evidência em campo, já que nessas condições a semente encontra algumas adversidades para germinar. De acordo com Silva et al. (2012), a qualidade das sementes de feijão é afetada pelas condições ambientais no período do seu desenvolvimento no campo e pelas condições de colheita, secagem, beneficiamento e armazenamento.
Deve-se considerar que o maior vigor da semente melhora 0 estabelecimento da cultura em campo, aumenta a uniformidade do estande e, consequentemente, possibilita incremento na produtividade. Segundo Carvalho e Nakagawa (2012), qualquer atraso ou diminuição na velocidade do processo de germinação aumenta a suscetibilidade das sementes a ataques de microrganismos presentes no solo, reduzindo assim a emergência de plântulas e, 
como consequência, comprometendo o estande final da lavoura.

$\mathrm{Na}$ Tabela 3 estão contidos os dados de comprimento da parte aérea (PA), raiz e massa seca de plântulas. Para o comprimento de plântulas, averiguouse os maiores resultados nas plântulas oriundas das sementes de São João-PE $(13,41 \mathrm{~cm}$ - PA e 13,61 cm - RAIZ), diferindo das demais localidades.

Tabela 3. Comprimento da parte aérea (PA), raiz e massa seca (MS) de plântulas oriundas de sementes de feijão crioulas de diferentes localidades.

\begin{tabular}{llll}
\hline Localidade & PA $(\mathbf{c m})$ & RAIZ $(\mathbf{c m})$ & MS $(\mathbf{g})$ \\
\hline São João-PE & $13,41 \mathrm{a}$ & $13,61 \mathrm{a}$ & $0,2695 \mathrm{a}$ \\
Lajedo-PE & $10,70 \mathrm{~b}$ & $8,80 \mathrm{c}$ & $0,2393 \mathrm{a}$ \\
Caetés-PE & $10,40 \mathrm{~b}$ & $12,50 \mathrm{~b}$ & $0,1870 \mathrm{~b}$ \\
União dos Palmares-AL & $9,50 \mathrm{c}$ & $6,68 \mathrm{~d}$ & $0,2311 \mathrm{a}$ \\
$\mathrm{CV}(\%)$ & 18,11 & 15,11 & 16,58 \\
\hline
\end{tabular}

Médias não diferem entre si a $5 \%$ de probabilidade pelo teste de Tukey.

Com relação à massa seca de plântulas, os maiores resultados foram constatados nos lotes das localidades São João, Lajedo e Caetés-PE, não diferindo estatisticamente entre si. Já o menor valor de MS foi obtido em Caetés $(0,1870 \mathrm{~g})$ (Tabela 3). Ramos et al. (2004) relatam que as avaliações da massa seca de plântulas são de grande importância na análise do desenvolvimento destas, assegurando 0 estabelecimento das mesmas no campo.

\section{CONCLUSÃO}

O lote proveniente do município de São João apresentou maior potencial de emergência e vigor em relação às demais variedades estudadas.

\section{AGRADECIMENTOS}

A todos que fazem parte do Laboratório de Propagação de Plantas (CECA/UFAL) pelo apoio na realização da pesquisa.

\section{REFERÊNCIAS}

AVACI, A. B.; COELHO, S. R. M.; NÓBREGA, L. H. P.; ROSA, D. M.; CHRIST, D. Qualidade fisiológica de sementes de feijão envelhecidas em condições de alta temperatura e umidade relativa. Publicativo UEPG - Ciências Exatas e da Terra, Agrária e Engenharias, 2010. 16, 33-38.

BRASIL. Ministério da Agricultura, Pecuária e Abastecimento. Regras para análise de sementes. Ministério da Agricultura, Pecuária e Abastecimento.
Secretaria de Defesa Agropecuária. Brasília: MAPA/ ACS. 2009. 395p.

BEZERRA, A. M. E.; MOMENTÉ, V. G.; MEDEIROS FILHO, S. Germinação de

sementes e desenvolvimento de plântulas de moringa (Moringa oleifera Lam.) em função do peso da semente e do tipo de substrato. Horticultura Brasileira, 2004, 22, 295-299.

CARVALHO, N. M.; NAKAGAWA, J. Sementes: ciência, tecnologia e produção. 5.ed. Jaboticabal: FUNEP, 2012. 590p.

CATÃO, H. C. R. M.; COSTA, F. M.; VALADARES, S. V.; DOURADO, E. da R.; BRANDÃO JUNIOR, D. DA S.; SALES, N. de L. P. Qualidade física, fisiológica e sanitária de sementes de milho crioulo produzidas no norte de Minas Gerais. Ciência Rural, 2010, 40, 2060-2066.

FRANÇA, C. G.; DEL GROSSI, M. E.; MARQUES, V. P. M. A. (Ed.). $O$ Censo

Agropecuário 2006 e a Agricultura familiar no Brasil. Brasília, DF: MDA, 2009. 96 p.

FERREIRA, D. F. Sisvar: a computer statistical analysis system. Ciência e Agrotecnologia, 2011, 35, 1039-1042.

MAGUIRE, J. D. Speed of germination-aid selection and evaluation for seedling emergence and vigor. Crop Science, 1962, 2, 176-177. 
PELWING, A. B.; FRANK, L. B.; BARROS, I. I. B. SILVA, A. L. da; SILVA, J. F. da; ALMEIDA, F. de A. Sementes crioulas: 0 estado da arte no Rio Grande do C.; GOMES, J. P.; ALVES, N. M. C.; ARAUJO D. R. Sul. Revista de Economia e Sociologia Rural, 2008, 46, Qualidade fisiológica e controle de sementes de milho 391-420. tratadas com Piper nigrum. Revista Brasileira de RAMOS, K. M. O.; FELFILI, J. M.; FAGGI, C. W.; Produtos Agroindustriais, 2012, 14, 131-142.

SOUZA-SILVA, J. C.; FRANCO, A. C. Crescimento inicial e repartição da biomassa de Amburana cearensis (Allemao) A. C. Smith. Em diferentes condições de SILVA, O. F.; WANDER, A. E. O feijão-comum no Brasil: Passado, Presente e Futuro. Embrapa-CNPAF, Santo sombreamento. Acta Botânica Brasílica, 2004, 18, 351Antônio de Goiás, 2013. 63p.

358. 